\title{
An experimental test on dynamic consumption and lump-sum pensions
}

\author{
Enrique Fatás · Juan A. Lacomba • \\ Francisco Lagos • Ana I. Moro-Egido
}

Received: 19 June 2011 / Accepted: 6 June 2013 / Published online: 19 June 2013

(C) The Author(s) 2013. This article is published with open access at SpringerLink.com

\begin{abstract}
This article examines the potential risks on consumption behavior of lumpsum payments. As a pension, lump-sum payments could be consumed too fast and generate an increase of poverty rates. We experimentally investigate consumption behavior in an inter-temporal decision-making setting. Subjects make consumption and saving decisions in an environment with two central features: first, there exists a decreasing probability of survival; and second, in addition to the regular income they get while active, they receive a unique lump-sum payment when retired. The results of this experiment show that rather than consuming too much during their income periods, subjects show a persistent precautionary saving behavior and over-save in the vast majority of periods. This result seems to be mainly driven by the risk averse individuals.
\end{abstract}

\footnotetext{
We thank people from CREED (Amsterdam) for helpful comments during the elaboration of the experimental design and seminar participants at Malaga, Tucson, Granada and Rome. Financial support from the Spanish Ministry of Education and Science (SEJ2009-11117/ECON) and Junta de Andalucía (P07-SEJ-03261) is gratefully acknowledged.
}

Electronic supplementary material The online version of this article (doi:10.1007/s13209-013-0098-y) contains supplementary material, which is available to authorized users.

\author{
E. Fatás \\ LINEEX, Faculty of Social Sciences, University of East Anglia, Norwich, UK \\ e-mail: E.Fatas@uea.ac.uk
}

\section{J. A. Lacomba · F. Lagos $(\varangle) \cdot$ A. I. Moro-Egido}

Departament of Economics, Faculty of Economics, University of Granada, Campus La Cartuja s/n, 18071 Granada, Spain e-mail: fmlagos@ugr.es

\section{J. A. Lacomba}

e-mail: jlacomba@ugr.es
A. I. Moro-Egido
e-mail: aimoro@ugr.es 
Keywords Experimental test · Consumption - Savings · Lump-sum payment

JEL Classification C91 $\cdot$ H55 $\cdot$ J26

\section{Introduction}

The reform of Social Security systems is now one of the main issues on the economic policy agenda of most industrialized countries. It is widely considered that, unless serious changes take place, the aging of the population implying a rise in the number of retirees relative to that of workers will threaten the viability of Pay-As-You-Go public pension systems in the long-run. With the aim of eliminating these future financing problems, one of the main goals of pension reforms is to raise the average age of retirement of workers

Orszag (2001), related to U.S. Social Security, considered that transforming Social Security's delayed retirement credit (given to people working between the ages of 62 and 65 in the U.S.) into a lump-sum payment rather than an increased monthly payment would likely encourage people to defer retirement. This question is addressed in Fatas et al. (2007). They find that the more concentrated the payments (shifting from annuity into lump-sum), the more postponed the retirement decisions.

Besides, it is likely that this transformation including a lump-sum payment would be relatively easy to implement. In the U.S. private industry, whose retirement benefits may be distributed in several alternative ways, using some type of lump-sum benefit as a payment option has become popular as an alternative to annuity payments (see Moore and Muller 2002; Blostin 2003 or Butrica et al. 2006). ${ }^{1}$ The Financial Times reported in July 2011 that $79 \%$ of polled pensioners collecting a company or private pension that year took a lump sum at their retirement.

However, although this type of proposal is outside of the current public pensions debate, the incorporation of a lump-sum payment as a measure to delay retirement decisions should require further analysis before receiving full consideration by policymakers.

Little is known about how quickly retirees would spend down their lump-sum payments, or how these reforms would affect consumption patterns. Butrica et al. (2006), using data from the Health and Retirement Study (HRS), examine how household expenditures among adults aged 65 and older vary by the degree of annuitization. They find that if Social Security was completely privatized, and retirees did not annuitize, discretionary spending could increase by as much as 22 percent for married adults and 38 percent for unmarried adults. However, other studies have shown that consumption usually declines at retirement. This decline has increasingly been referred to as the retirement consumption puzzle. See Fisher et al. (2005) for references.

\footnotetext{
1 Additionally, Fetherstonhaugh and Lee Ross (1999), using a questionnaire, find evidence that people would be more willing to delay retirement if they received a lump-sum payment rather than an increased annuity.
} 
These opposite results suggest that more research is needed before unambiguous conclusions can be made. This is precisely the aim of this work: to provide additional empirical evidence to this debate. To this end, we consider an experimental investigation to test the potential effects on consumption behavior of implementing a lump-sum payment in a public pension system. We also analyze how closely the predictions of the optimality theory fit the actual behavior of subjects in a lab.

Over the last two decades, there has been a steady increase in the applications of laboratory methods on economic questions. As Falk and Fehr (2003) state, one of the strengths of experimental methods is that we can empirically study the effects of different institutional environments, as defined by their rules and incentives. The precise observation of human behavior in experiments also forces the researcher to take issues of human motivation and bounded rationality more seriously. In the long run, this is likely to generate a more realistic picture of human nature. In this sense, lab experiments should not be viewed as substitutes but as complements to more traditional methods of empirical economic analysis.

Our paper contributes to the experimental literature dealing with saving-consumption behavior (Camerer and Chua 2005; Carbone and Hey 2004; Ballinger et al. 2004; Brown et al. 2006). To our knowledge, this is the first experimental approach to examine a dynamic saving-consumption problem in a retirement framework. ${ }^{2}$ In this sense, this paper also contributes to the literature on retirement behavior and pension plans (Breyer and Kifmann 2002; Fehr et al. 2003; Fatas et al. 2007; among others).

The experimental design is based on two central features: first, there exists a decreasing probability of surviving which implies an uncertain future income; and, secondly, there are two sequences of income, one when individual works and another when she is retired. While working, subjects earn a constant wage and at the beginning of their retirement period they receive the present value of the total pension benefits as a unique lump-sum payment.

The results of this paper indicate that in the vast majority of periods subjects oversave rather than over-consume. This result holds for both the periods prior to the lump-sum payment and the no income periods, when smoothing becomes more difficult. We also find that subjects over-react to the lump-sum payments, as they briefly consume above their optimal dynamic consumption paths. However, and on aggregate, the general picture goes in the opposite direction. Subjects, rather to consume their available income immediately after the lump-sum period, keep on smoothing their consumption and adjust it to the optimal path in a more than reasonable way.

An additional risk, pointed by Orszag (2001), would come from the political pressure to extend lump-sum payments to those who are younger than the regular retirement age. Such an extension would raise the risk of increasing elderly poverty rates. In order to study the consequences of such a possibility, we ran a second treatment moving the lump-sum payment into earlier periods (increasing the number of

\footnotetext{
2 In a retirement and experimental benchmark, Agnew et al. (2008) designed an experiment to examine the role of gender in the choice between purchasing an annuity or investing their savings on their own. Gazzale and Walker (2009) also conducted a lab experiment to systematically investigate the low rate of retirement-asset annuitization relative to the predictions of standard models. However, none of these papers consider saving-consumption decisions.
} 
periods with no income at all). It also has to be noted that we consider actuarially fair pension systems and therefore in this second treatment the lump-sum payment is also smaller. Data show that subjects tend to over-react even more and adopt stronger precautionary saving measures in this second treatment. The result of over-saving behavior seems to be mainly driven by the risk averse individuals. Additionally, in order to identify the determinants of the consumption behavior, we run some regressions. One of our findings that could explain the over-saving behavior is that subjects do not consider their available cash when dealing with consumption decisions. Thus, our results suggest that Social Security reforms aimed at moving from traditional annuitized pensions to lump-sum payments might not yield increases in poverty rates.

This paper is organized as follows. Section 2 briefly surveys the experimental literature on this topic. Section 3 develops the theoretical model, while Sect. 4 presents the experimental design and procedures. Section 5 presents our results and Sect. 6 concludes. All tables and figures are relegated to the Appendix.

\section{Experimental background}

In the experimental literature into consumption behavior under uncertainty there exist few contributions but relevant ones. For instance, Hey and Dardadoni (1988) describe a large-scale experimental investigation to test the implications of expected utility maximization on optimal consumption behavior. They find that the actual behavior in the lab differs significantly from the optimal behavior, and that the comparative static implications of actual behavior agree with those of optimality theory. Carbone and Hey (2004) investigate the over-sensitivity of consumption to current income. They adopt a simple model in which income in any period can take just one of two values: employment and unemployment. Unlike neoclassical theoretical predictions about smooth consumption over time, they find that subjects over-react. That is, their results show a close relationship between consumption and current income.

On the other hand, Ballinger et al. (2004) study social learning about the life cycle saving task. They use experimental methods to study a household inter-temporal choice problem. Subjects participate in three-member "families". Second and third "generation" subjects observe and/or communicate with their "antecedent" first or second generation subject. They find that later generations perform significantly better than earlier generations. Brown et al. (2006) establish potential ways in which consumers can attain near-optimal consumption behavior. In line with Ballinger et al. (2004), individual and social learning mechanisms are proposed to be one possible link. They find that while consumers persistently spend too much in early periods, they learn rapidly from their own experience and from experience of others to consume amounts close to optimal levels.

Our work presents some interesting differences with regard to all above mentioned papers. In order to investigate saving-consumption decisions in a retirement benchmark, we introduce two novel features. First, subjects face a decreasing probability of surviving across periods. Second, participants receive three different levels of income according to a retirement period ( $\mathrm{R}$ hereafter): (i) a constant level of income during 
each period before $\mathrm{R}$ (as worker); (ii) a higher lump-sum of income in $\mathrm{R}$ (the first period as retired); and (iii) nothing from $\mathrm{R}$ on.

\section{The model}

Before we proceed with the experimental design and results, in this section we are going to characterize the optimal consumption decisions using a standard model. Consider an individual who has to decide on his optimum consumption at different age in presence of uncertainty about the length of life. Suppose that this is the only uncertainty that the individual faces. Let $T>0$ be the planning horizon, that is, maximum lifetime. Lifetime uncertainty is presented by a survival distribution function, $F(t)$ non increasing in age, $0 \leq t \leq T$, that satisfies $F(0)=1 .^{3}$ All individuals are assumed to have the same survival distribution function. 4

Denote consumption at age $t$ by $c(t)$, where $c(t) \geq 0$. Utility from consumption at different ages is separable and independent of age. There is no subjective discount rate. ${ }^{5}$ We use a specific utility function, $u(c)$ that displays risk-aversion, and to ensure an interior solution, satisfies the Inada conditions. ${ }^{6}$ While working, the individual provides one unit of labor. Contingent on survival, the individual works between ages 0 and $R, 0<R<T$, that is, there exists a mandatory retirement age that occurs at $R$. The individual's objective function is to maximize the non discounted expected utility $V$

$$
V=\sum_{\mathrm{t}=1}^{\mathrm{T}} \mathrm{F}(\mathrm{t}) \mathrm{u}(c(t))
$$

Let wages at age t, be $w(t) \geq 0$. Savings earn a zero rate of interest. ${ }^{7}$ With no initial assets, the individual's assets at age t, $S(t)$, are equal to the cumulative savings. Feasible consumption plans must have non-negative assets at all ages

$$
S(t)=\sum_{\mathrm{j}=1}^{\min (\mathrm{t}, \mathrm{R})} \mathrm{w}(\mathrm{j})-\sum_{\mathrm{j}=1}^{\mathrm{t}} c(j) .
$$

We assume that $w(t)=w$ for all $0<t<R$, therefore the restriction becomes

$$
S(t)=\min [(R-1) w, t w]-\sum_{\mathrm{j}=1}^{\mathrm{t}} c(j) .
$$

\footnotetext{
3 In a theoretical background it also requires that $F(T)=0$.

4 See third column in Table 1.

5 For the sake of simplicity we choose a zero discount rate.

6 Conditions for risk aversion are $\mathrm{u}^{\prime}(\mathrm{c})>0$ and $\mathrm{u}^{\prime \prime}(\mathrm{c})<0$. The Inada conditions imply that $\mathrm{u}^{\prime}(0)=8$ and $\mathrm{u}^{\prime}(8)=0$. The specific utility function for implementing the experiment is $\mathrm{u}(\mathrm{c})=10 *$ square root $(\mathrm{c})$.

7 For the sake of simplicity we choose a zero discount rate.
} 
The choice of the optimum consumption path will depend on the insurance options available. Relative to this benchmark case, we analyze an alternative scenario, in which individuals will receive a unique lump-sum payment at the beginning of the retirement period. The total value of expected contributions has to be equal than the lump-sum payments, that is,

$$
\sum_{\mathrm{t}=1}^{\mathrm{R}-1} \mathrm{~F}(\mathrm{t}) \tau \mathrm{w}=F(R) \mathrm{LS}
$$

then the lump-sum payment is

$$
L S=\tau \mathrm{w} \frac{\sum_{\mathrm{t}=1}^{\mathrm{R}-1} \mathrm{~F}(\mathrm{t})}{F(R)}=\tau \mathrm{w} H(R) .
$$

Restriction on savings is now

$$
S(t)=\min [L S, t(1-\tau) w]-\sum_{\mathrm{j}=1}^{\mathrm{t}} c(j) \quad \forall t \in[1, R]
$$

This theoretical model will be used to measure to which extent subjects deviate form the optimal consumption path in the experiment.

\section{Experimental design and procedures}

Our experimental design tries to capture some actual features of an actuarially fair public pension system with a unique lump-sum payment. ${ }^{8}$ The experiment consists of three sequences of at most 30 rounds and one decision per round. See Table 1 into Appendix.

Each round is characterized by a probability of surviving. As the round number increases, the probability of surviving decreases. In each round reached, subject either survives or not. A subject reaches a round if, and only if, she has survived all earlier rounds.

During the first $R-1$ rounds, similar to wage earnings, subject receives 85 experimental units in each reached round (Income).

In round $R$, subjects receive the present value of the total pension benefits as a unique lump-sum payment. As abovementioned, as a strategy to analyze what would happen with savings and spending decisions if lump-sum payments where extended to those who retire earlier than the regular retirement age, we design two treatments. In Treatment 1 (hereafter LS10) the round $R$ is the 10th and in Treatment 2 (hereafter $\mathrm{LS} 15$ ) the round $R$ is the 15 th.

\footnotetext{
8 Reforms aiming to achieve actuarially fair social security systems must adjust pension benefits to achieve that the increase in pension benefits be exactly offset by the higher cost in terms of contributions and foregone pensions.
} 
We consider a gross wage of 100 experimental units and a tax rate of $15 \%$. Thus, in order to reflect an actuarially fair pension system, the lump-sum payment in LS10 is equal to 191.25 experimental units (with $\mathrm{R}=10$ ) and in LS15 is equal to 345 experimental units (with $\mathrm{R}=15$ ) following Eq. (5).

In the remaining rounds subjects receive no income at all. Therefore, in LS10 and in LS15 subjects have at most 19 and 14 rounds with no income, respectively.

In each round subjects have to make a unique decision about how to divide the Available Cash into consumption and savings. The available cash comes from the addition of the income received in that period and what is not consumed in previous rounds (their cumulative savings). So, income can be saved to provide wealth but savings earn no interest. Additionally, borrowing is not allowed, that is, subjects cannot spend more than their Available Cash.

Let $C$ denote the amount of experimental units converted into points by subjects in each round (their consumption). Subjects are informed of the conversion scale (from experimental units to points, converted into real euros at the end of the experiment): $C$ experimental units generate $20 *$ square root $(C)$ points. A table mapping how different consumption choices are converted into points is given separately to subjects.

As mentioned above, subjects play three sequences. They are told that at the end of the experiment they will be privately paid in cash the total amount of points converted from experimental units of one of the three sequences (randomly chosen). They are also told that any unconverted experimental unit remaining at the end of any sequence is worthless.

A total of 39 undergraduate students in Business and Economics from the University of Valencia took part in the experiment. All sessions were run at the Laboratory for Research in Experimental Economics (LINEEX) and standard electronic recruitment procedures were used to collect the subject pool. All subjects participating in the experiment had previously participated (weeks before the experiment was run) in other sessions facing a Raven test, a risk aversion test and a basic socioeconomic survey. ${ }^{9}$ The list of participants in every session was randomized to control for any reputation or group identity effect. Anonymity was preserved using random codes and these tests were paid independently.

At the beginning of the experiment, subjects entered the laboratory and were randomly seated in a private cubicle. Experimental instructions were read aloud by the experimenter. ${ }^{10}$ To make sure subjects understood the logic of the game, subjects completed a quiz before the experiment began. Explanations were repeated until all subjects passed the quiz (nobody made a mistake almost from the beginning, quiz available from authors upon request).

\footnotetext{
9 The electronic recruitment system at LINEEX follows a quite natural mechanism. The University of Valencia students get an email from the laboratory, announcing new sessions. They then go to a web based system to register in a given session, depending on their prior experience and the session requirements. The risk aversion test was the one by Holt and Laury (2002), based on a menu of ten paired lottery choices. Decisions in our experiment were matched with the decisions in the test by a common random code subjects used in both sessions. Identities were never linked to choices.

10 Instructions are available upon request from the authors.
} 
At the end of the experiment subjects were privately paid with an exchange rate of 125 points $=€ 1$ for one of the three sequences, chosen at random. On average an experimental session lasted $<90 \mathrm{~min}$, the average earnings were around $€ 27$ and the maximum earnings peaked above $€ 40$.

The experiment consisted of two treatments: LS10 and LS15. 20 subjects participated at LS10 and 19 subjects at LS15.

\section{Results}

Table 2 presents the summary statistics of the individuals' decisions about consumption, their cumulative savings and available cash at the beginning of each period, for both the LS10 and LS15 treatments, by sequences. The number of survived periods in the last row denotes the average number of rounds that subjects were alive and making decisions. Average life is almost identical in both treatments (16.7 versus 16.58, as expected in a pure randomly driven process).

By pure inspection, average consumption is higher in LS15 than in LS10. This follows the experimental design, as subjects get a higher lump-sum and get a positive income during a higher number of periods in LS15. However, the more interesting information regarding treatment effects comes from the next two variables. Both the average cumulative savings and the available cash are a direct consequence of subjects' decisions in both treatments. Again, by pure inspection, subjects save considerably more in LS10 (152.8) than in LS15 (101.4): the difference is around 50\%. This suggests that subjects in the worst scenario are able to save more to protect themselves from the higher number of periods with no income. Moreover, the average available cash is larger in LS10, in spite of the fact that available cash is the sum of cumulative savings and income (by definition, larger in LS15 than in LS10). Over-saving behaviour in LS10 more than compensates this difference.

No clear differences are observed across sequences within each treatment in consumption and savings. The actual consumption and saving choices do not show a clear (increasing or decreasing) trend as participants play more sequences. However, the standard deviation falls as subjects make more decisions. Besides, this reduction in the standard deviation across sequences seems to be systematic for all available variables. That is, in a very preliminary way, subjects seem to adjust better as the number of decisions increases.

The descriptive information shown above is not enough to answer our main research question. In order to learn about subjects' capabilities to get close to the optimal consumption path, we need to measure the distance between actual decisions and our theoretical benchmark.

We include two measures of divergence between actual and optimal behaviour. In our view, there are two plausible ways of thinking about optimality in this context. The first way is to define optimal consumption as the level of consumption calculated in the first period for the rest of the life-time profile. We will call this optimal consumption the ex-ante optimal consumption (EAOC). To compute EAOC we solve the dynamic optimization problem in period zero to find the optimal smoothed consumption path. 
The policy consequences of this approach to optimal decisions are straightforward: EAOC would be the rational choices done by a benevolent social planner.

The second approach to optimality takes as the natural analysis unit the per-round individual decision. For every subject and every available cash amount, based on her previous decisions, we compute the optimal consumption for every period, contingent on the fact that (i) she is alive and (ii) owns a given actual positive wealth. This alternative approach is a kind of natural basis for assessing the optimality of subjects' decisions dynamically. We call this ex-post optimal consumption (EPOC).

Note that EAOC and EPOC have different meanings. The natural interpretation for EAOC comes from the policy side: it is a general average measure of the adjustment of the population (in our case, the subject pool) to the optimal path in welfare terms. Significant deviations in this ex ante measure can be associated to welfare losses. EPOC gives additional valuable information about the optimality of decisions at the individual level. For every subject, in every period, it defines the optimal decision, contingent on the fact that she is still making decisions over her individual level of wealth.

To facilitate the comparison of actual and optimal consumption levels over all individuals we plot them. Figures 1 and 2 ( 3 and 4 ) correspond to average consumption and cumulative savings in LS10 (LS15). In Figs. 1 and 3, the actual consumption paths are compared with EAOC and EPOC, while the associated optimal cumulative savings are used in Figs. 2 and 4.

In these comparisions a risk aversion rate of 0.50 is used. The reason is the following. A constant risk aversion rate of 0.50 is implicitly used in the payoff function converting points into earnings. ${ }^{11}$

Unlike previous experimental papers, we find no evidence of over consumption in the first rounds. On the contrary, our participants under-consume in this earliest periods. ${ }^{12}$ This under-consumption behaviour lasts until round 5 in LS10 and round 10 in LS15 using the EAOC as a benchmark, while it holds in almost all rounds when the EPAC measure is used.

From an ex ante perspective, and before the lump-sum period comes, consumption exhibits some inertia and subjects fail to smooth it. Relative to the EAOC path, subjects over consume temporarily around the lump-sum period, in rounds 8-11 in LS10 and rounds 11-15 in LS15. However, this over consumption disappears when EPOC is used as the reference point. With the exclusion of the very same period when the lump sum is received, subjects under consume in all periods relative to the optimal path.

Interestingly, after the lump-sum payment period, when subjects get no income at all, participants in the experiment performed relatively well adjusting their behaviour to the optimal path. Rather to consume their available income immediately after the lump-sum period, they keep on smoothing their consumption and adjust it to the optimal path in a more than reasonable way.

\footnotetext{
11 As the conversion involves no uncertainty at all, this parameter is only a design artifact to generate a concave payoff function and allow for some consumption smoothing. Similar design features have been used in the related literature, described in Sect. 2.

12 We denote by earliest periods the pre lump-sum rounds, that is, the 10 first rounds in LS10 and the 15 first rounds in LS15.
} 
A natural way to back up these descriptive comments is to have a look at the evolution of cumulative savings over time in Figs. 2 and 4. Subjects perform saving choices in a relatively poor manner, in the sense that they over-save in all periods in LS10. In LS15 subjects also over-save in a vast majority of periods, with the notable exception of periods around the lump-sum payment, when their reaction to the sharp increase in income is not compensated by a parallel jump in savings. ${ }^{13}$ This general behavioural pattern does not change after receiving the lump-sum payment. It suggests that savings tend to be precautionary, with the exception of the periods in which the high lump-sum is received.

Before we proceed with a more formal analysis of the experimental data it is worth to note that our design can be considered as a kind of a strong test for over-saving (and under-consumption). On the one hand, in Hey and Dardadoni (1988) and Carbone and Hey (2004) the rate of return per period is known and certain, for all money saved. On the other, in Ballinger et al. (2004) and Brown et al. (2006) the incentives to save money are embedded in their particular utility function, so saving is salient for subjects.

In our experimental design savings yields no returns. Our utility function, though concave, differs of the ones used by Ballinger et al. (2004) and Brown et al. (2006) to avoid the salience of saving money. Additionally, subjects were not punished in any specific way when their consumption was critically low, as no negative utility was associated to a zero consumption level. We additionally paid very much attention to keep framing as neutral as possible to avoid any kind of demand effect.

In order to check whether our results are robust to changes in risk aversion rates, we make a second analysis. We compare the actual and optimal consumption levels for different risk aversion coefficients (risk averse, risk neutral and risk loving). ${ }^{14}$ See Figs. 5, 6, 7 and 8. Our results show that the risk averse individuals mainly drive the over-saving. Note that, as in the general case discussed above, the actual cumulative saving before the lump-sum payment is higher than the optimal one under EAOC and EPOC. For the case of risk neutral and risk loving individuals, the over-saving no longer exists, except for the case of EPOC for risk neutral individuals in both treatments (LS10 and LS15). Therefore, we can conclude that the existence of oversaving is mostly due to the individual's risk aversion.

In a more formal way, we run some regressions to explore the determinants of decisions. To control for the dependency of the observations from a single subject we use clustering to avoid that the t-values are extremely overestimated. The dependent variable is the log of absolute deviation from optimality (both relative to EAOC and EPOC: LD-EAOC and LD-EPOC considering each particular risk aversion value). A negative coefficient means that the corresponding independent variable lowers the deviation from optimality. Since the dependent variable is the logged deviation, the coefficient means that a variable causes a certain percentage of increase or decrease in deviation relative to when this variable is absent.

\footnotetext{
13 The optimal consumption peaks at the retirement period because of the lump-sum payment. This peak is larger is LS15 due to the lump-sum payment is larger and the probability of surviving, when it is received, is much lower.

14 We would like to thank to an anonymous referee for pointing out the importance of making such comparisons.
} 
We consider different groups of explanatory variables. Dumbreak is a dummy that takes the value of 1 for all LS10 data, 0 otherwise, and it intends to capture the existence of any treatment effect. Seq2 (Seq 3) takes the value of 1 when data is generated in the second (third) sequence of 30 rounds.

As the probability of survival decreases with the number of periods played, we include both a Period and a Period Squared variable. Hand in hand with the increasing uncertainty (measured by the decreasing probability of survival), we expect participants to make worse decisions as the number of periods increases, so we expect a positive coefficient for this variable. The Period Squared variable simply takes into account any possible non-linearity that the period variable may have.

Risk is the risk aversion of subjects, as measured by the Holt and Laury risk aversion test. The original value range (from 0 to 10 ), is decomposed into three values: 0 if subject is risk loving, 1 if she is risk neutral and 2 if she is risk averse. Raven Test $i s$ the ratio of correct answers in the test (a non verbal IQ test) run by all subjects participating in the experiment. Sex is a dummy variable to control for gender effects ( 0 for females, 1 for males). ${ }^{15}$ We report the estimation results in Table 3.

The first result emerging from Table 3 is that timing matters when dealing with lump sum schemes. Postponing the retirement period and getting the lump sum later, significantly increases the deviation from the optimal path. Even when subjects get a positive income fewer times in LS10, they are relatively better able to cope with the optimization problem and smooth their consumption over time.

No sequence dummy is significant, so our results suggest that there is very little learning across stages, if any. Coefficients on Period and Period Squared show that, as expected, deviations increase as more periods are played, but at a decreasing rate. Risk aversion is significant. Risk-averse subjects outperform risk lovers (as the negative coefficients show).

Following Brown et al. (2006), we want to check a natural behavioural explanation for the observed patterns of consumption based on either the existence of a "rule of thumb" (subjects simply spend a fixed fraction of their current income or a fraction of available cash) or that consumers spend a fraction of the conditionally optimal amount. To investigate these alternative explanations, we ran regressions in which the log of actual consumption is regressed against the optimal level of consumption and either current income or available cash (i.e., income plus cumulative savings). Table 4 summarizes these results. ${ }^{16}$

Table 4 suggests that subjects do not consider their available cash when dealing with consumption decisions. They mainly focus on their current income. Besides, the coefficient of Income is larger than that of Available cash, which means that subjects decide their consumption levels regardless of their savings. This is consistent

\footnotetext{
15 Additional socioeconomic variables are excluded from the analysis as they proved to be never significant in all estimations. Full estimations are available from authors upon request.

16 Fixed effects are included to adjust for the possibility that some subjects saved more than others. The estimates of those variables are omitted for the sake of simplicity. Although not in the table, we have also performed the analysis by sequence for any of the treatments. Since the results do not change we only present results by pooled data.
} 
with the over-saving behavioural pattern. The increment in the R-squared value is small when considering Available cash but large in the case of Income. Notice that this result is independent of ex-ante or ex-post considerations. However, unlike in the EAOC framework, we find that the optimal consumption also explains the consumption pattern in the EPOC framework.

\section{Conclusions}

More and more companies are giving the option of taking the pension as a lump sum distribution instead of an annuity payout. However, retirees need to carefully weigh out the pros and cons of a lump sum or annuity distribution before making this decision. People who do not annuitize much of their retirement wealth might spend too quickly the lump-sum payment reducing income at very old ages. In this paper we have tested in the laboratory the potential effects on consumption behavior of a lump-sum payment. Our main conclusion is that this might not be the case. The introduction of a unique lump-sum payment generates a behavioral overreaction in the opposite direction: rather than consuming too much, too fast, our subjects show a persistent precautionary saving behavior. This result seems to be mainly driven by the risk averse individuals, which are the most frequent type.

The picture that leaves our experiment is that transforming (at least, partially) pension benefits into lump-sum payments might not increase elderly poverty rates. Moreover, the earlier and the lower the lump-sum payment, the stronger the saving reaction.

It is always difficult to translate results from a lab experiment to behavior in the real world. Although the subjects of this experiment are both younger and more educated on average than the individuals who would take decisions in real life, results obtained are in line with some evidence on decision processes of real people in similar decisions. For instance, Hamermesh and Menchik (1987), analyzing bequests and the planning horizon and using a data set on wealthy decedents and their parents, state that there is a high average level of savings, far above what could be explained solely by planned saving for retirement. Thaler (1992) also finds that individuals are more likely to save a larger amount as the size of the lump sum increases.

In this sense, this experiment is a small step on the experimental analysis of consumption behavior by allowing us to illustrate the point obtained from a theoretical model with rational expectation agents.

Open Access This article is distributed under the terms of the Creative Commons Attribution License which permits any use, distribution, and reproduction in any medium, provided the original author(s) and the source are credited.

\section{Appendix}

See Tables 1, 2, 3, 4 and Figs. 1, 2, 3, 4, 5, 6, 7, 8 . 
Table 1 Experimental design

\begin{tabular}{|c|c|c|c|c|c|c|c|c|}
\hline Rounds & $\begin{array}{l}\text { Probability } \\
\text { of surviving }\end{array}$ & $\begin{array}{l}\text { Probability } \\
\text { of being } \\
\text { alive in each } \\
\text { period: } \mathrm{F}(\mathrm{t})\end{array}$ & $\begin{array}{l}\text { LS10 } \\
\text { income }\end{array}$ & $\begin{array}{l}\text { LS15 } \\
\text { income }\end{array}$ & $\begin{array}{l}\text { Available } \\
\text { cash }\end{array}$ & Consumption & Savings & $\begin{array}{l}\text { Obtained } \\
\text { points }\end{array}$ \\
\hline 1 & 1 & 1 & 85 & 85 & 85 & - & - & - \\
\hline 2 & $29 / 30$ & $29 / 30$ & 85 & 85 & & & & \\
\hline 3 & $28 / 29$ & $28 / 30$ & 85 & 85 & & & & \\
\hline 4 & $27 / 28$ & $27 / 30$ & 85 & 85 & & & & \\
\hline 5 & $26 / 27$ & $26 / 30$ & 85 & 85 & & & & \\
\hline 6 & $25 / 26$ & $25 / 30$ & 85 & 85 & & & & \\
\hline 7 & $24 / 25$ & $24 / 30$ & 85 & 85 & & & & \\
\hline 8 & $23 / 24$ & $23 / 30$ & 85 & 85 & & & & \\
\hline 9 & $22 / 23$ & $22 / 30$ & 85 & 85 & & & & \\
\hline 10 & $21 / 22$ & $21 / 30$ & 85 & 85 & & & & \\
\hline 11 & $20 / 21$ & $20 / 30$ & 191.25 & 85 & & & & \\
\hline 12 & $19 / 20$ & $19 / 30$ & & 85 & & & & \\
\hline 13 & $18 / 19$ & $18 / 30$ & & 85 & & & & \\
\hline 14 & $17 / 18$ & $17 / 30$ & & 85 & & & & \\
\hline 15 & $16 / 17$ & $16 / 30$ & & 85 & & & & \\
\hline 16 & $15 / 16$ & $15 / 30$ & & 345 & & & & \\
\hline 17 & $14 / 15$ & $14 / 30$ & & & & & & \\
\hline 18 & $13 / 14$ & $13 / 30$ & & & & & & \\
\hline 19 & $12 / 13$ & $12 / 30$ & & & & & & \\
\hline 20 & $11 / 12$ & $11 / 30$ & & & & & & \\
\hline 21 & $10 / 11$ & $10 / 30$ & & & & & & \\
\hline 22 & $9 / 10$ & $9 / 30$ & & & & & & \\
\hline 23 & $8 / 9$ & $8 / 30$ & & & & & & \\
\hline 24 & $7 / 8$ & $7 / 30$ & & & & & & \\
\hline 25 & $6 / 7$ & $6 / 30$ & & & & & & \\
\hline 26 & $5 / 6$ & $5 / 30$ & & & & & & \\
\hline 27 & $4 / 5$ & $4 / 30$ & & & & & & \\
\hline 28 & $3 / 4$ & $3 / 30$ & & & & & & \\
\hline 29 & $2 / 3$ & $2 / 30$ & & & & & & \\
\hline 30 & $1 / 2$ & $1 / 30$ & & & & & & \\
\hline
\end{tabular}


Table 2 Descriptive statistics

\begin{tabular}{|c|c|c|c|c|c|c|c|c|}
\hline \multirow[t]{2}{*}{ Averages } & \multicolumn{4}{|l|}{ LS10 } & \multicolumn{4}{|l|}{ LS15 } \\
\hline & Total & Seq $=1$ & Seq $=2$ & Seq $=3$ & Total & Seq $=1$ & Seq $=2$ & Seq $=3$ \\
\hline Consumption & $\begin{array}{l}43.82 \\
(44.20)\end{array}$ & $\begin{array}{l}49.32 \\
(50.51)\end{array}$ & $\begin{array}{l}40.27 \\
(44.61)\end{array}$ & $\begin{array}{l}43.74 \\
(36.62)\end{array}$ & $\begin{array}{l}66.22 \\
(44.65)\end{array}$ & $\begin{array}{l}65.89 \\
(50.35)\end{array}$ & $\begin{array}{l}68.11 \\
(44.18)\end{array}$ & $\begin{array}{l}65.11 \\
(40.47)\end{array}$ \\
\hline Cum. savings & $\begin{array}{l}152.8 \\
(187.35)\end{array}$ & $\begin{array}{l}148.0 \\
(198.69)\end{array}$ & $\begin{array}{l}149.6 \\
(187.81)\end{array}$ & $\begin{array}{l}161.4 \\
(176.36)\end{array}$ & $\begin{array}{l}101.4 \\
(135.31)\end{array}$ & $\begin{array}{l}111.8 \\
(144.99)\end{array}$ & $\begin{array}{l}89.4 \\
(128.05)\end{array}$ & $\begin{array}{l}102.5 \\
(132.75)\end{array}$ \\
\hline Available cash & $\begin{array}{l}196.6 \\
(191.28)\end{array}$ & $\begin{array}{l}197.3 \\
(197.28)\end{array}$ & $\begin{array}{l}189.9 \\
(196.21)\end{array}$ & $\begin{array}{l}205.2 \\
(179.00)\end{array}$ & $\begin{array}{l}167.6 \\
(135.89)\end{array}$ & $\begin{array}{l}177.7 \\
(144.09)\end{array}$ & $\begin{array}{l}157.5 \\
(127.74)\end{array}$ & $\begin{array}{l}167.6 \\
(135.25)\end{array}$ \\
\hline \# Survived periods & $\begin{array}{l}16.70 \\
(9.37)\end{array}$ & $\begin{array}{l}13.75 \\
(9.10)\end{array}$ & $\begin{array}{l}20.90 \\
(8.52)\end{array}$ & $\begin{array}{l}15.45 \\
(8.96)\end{array}$ & $\begin{array}{l}16.58 \\
(8.86)\end{array}$ & $\begin{array}{l}14.79 \\
(9.52)\end{array}$ & $\begin{array}{l}14.63 \\
(8.11)\end{array}$ & $\begin{array}{l}20.31 \\
(7.63)\end{array}$ \\
\hline \# Obs. & 1,002 & 275 & 418 & 309 & 945 & 281 & 278 & 386 \\
\hline
\end{tabular}

Standard errors in brackets

Table 3 Regression analysis

\begin{tabular}{|c|c|c|}
\hline & LD-EAOC & LD-EPOC \\
\hline \multirow[t]{2}{*}{ Dumbreak } & -0.611 & -0.382 \\
\hline & $(1.815)$ & $(1.863)$ \\
\hline \multirow[t]{2}{*}{ Seq 1} & -0.498 & -0.400 \\
\hline & $(0.580)$ & $(0.559)$ \\
\hline \multirow[t]{2}{*}{ Seq 2} & -0.849 & -0.818 \\
\hline & $(0.653)$ & $(0.657)$ \\
\hline \multirow[t]{2}{*}{ Period } & $0.260 * * *$ & $0.277 * * *$ \\
\hline & $(0.076)$ & $(0.072)$ \\
\hline \multirow[t]{2}{*}{ Period squared } & $-0.013^{* * *} *$ & $-0.014 * * *$ \\
\hline & $(0.003)$ & $(0.003)$ \\
\hline \multirow[t]{2}{*}{ Raven test } & -0.028 & -0.037 \\
\hline & $(0.048)$ & $(0.050)$ \\
\hline \multirow[t]{2}{*}{ Sex } & 0.191 & 0.170 \\
\hline & $(0.909)$ & $(0.912)$ \\
\hline \multirow[t]{2}{*}{ Risk } & $0.963 * *$ & $1.026 * *$ \\
\hline & $(0.416)$ & $(0.414)$ \\
\hline \multirow[t]{2}{*}{ Constant } & 1.442 & 0.899 \\
\hline & $(1.943)$ & $(2.051)$ \\
\hline Observations & 1,361 & 1,361 \\
\hline $\mathrm{R}$-squared & 0.155 & 0.156 \\
\hline
\end{tabular}


Table 4 Behavioral analysis

\begin{tabular}{lllll}
\hline Consumption & Exante & \multicolumn{3}{l}{ Expost } \\
\hline Optimal consumption & -0.009 & -0.300 & $0.229 * *$ & $0.524 * * *$ \\
& $(0.234)$ & $(0.275)$ & $(0.087)$ & $(0.121)$ \\
Income & $0.364 * * *$ & & $0.348^{* * *}$ \\
& $(0.101)$ & & $(0.102)$ & \\
Available cash & & 0.001 & & 0.002 \\
& & $(0.010)$ & & $(0.010)$ \\
Observations & 1,361 & 1,361 & 1,361 & 1,361 \\
R-squared & 0.39 & 0.27 & 0.39 & 0.29 \\
\hline
\end{tabular}

Standard errors in brackets

* significant at $10 \%$;

** significant at $5 \%$;

*** significant at $1 \%$

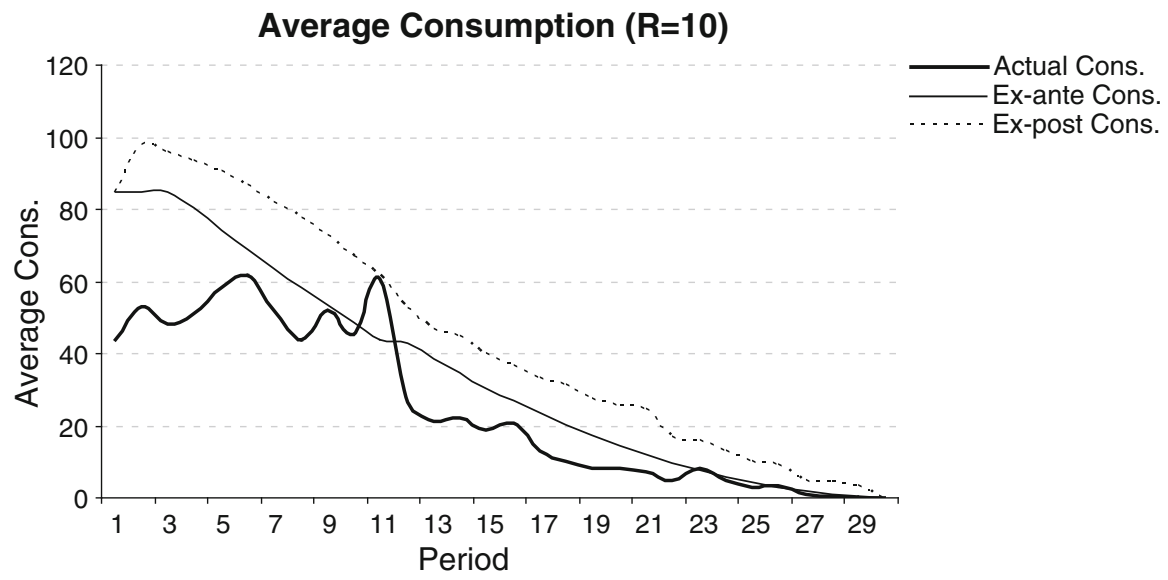

Fig. 1 Consumption in treatment LS10

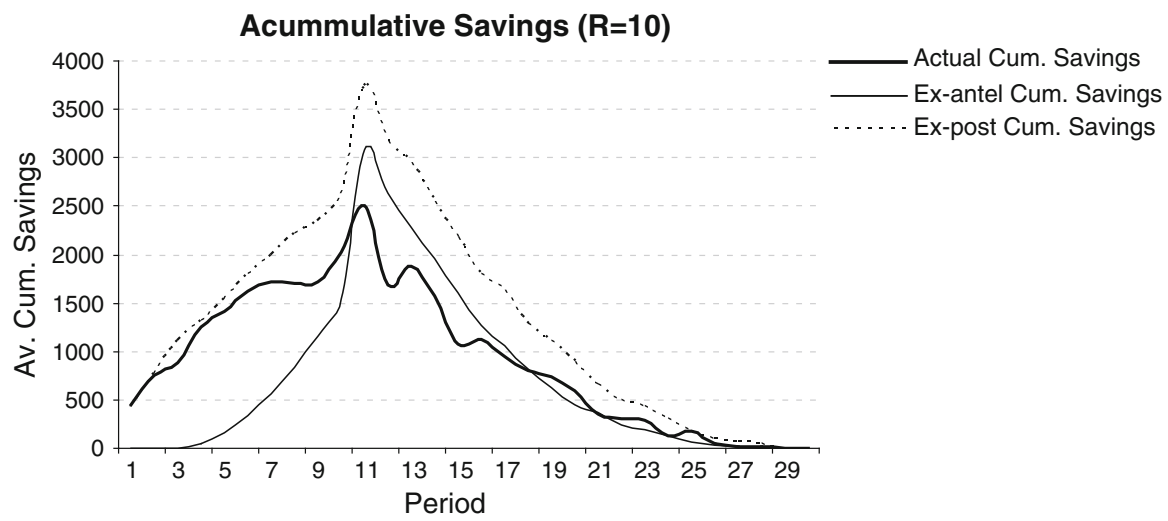

Fig. 2 Cumulative savings in treatment LS10 


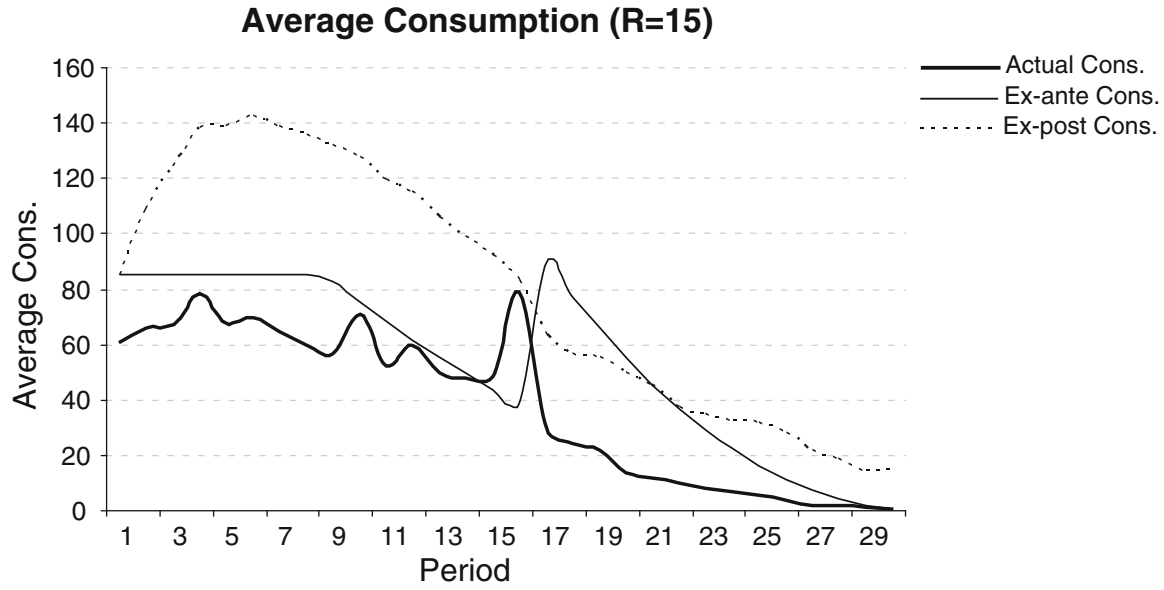

Fig. 3 Consumption in treatment LS15

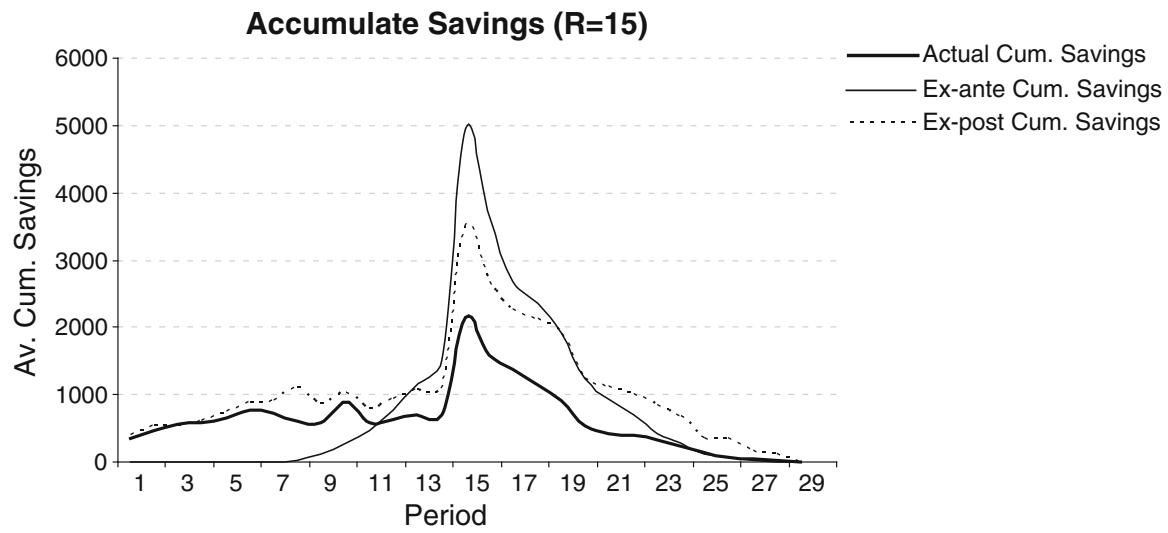

Fig. 4 Cumulative savings in treatment LS15 
Average Consumption ( $R=10$, Averse)

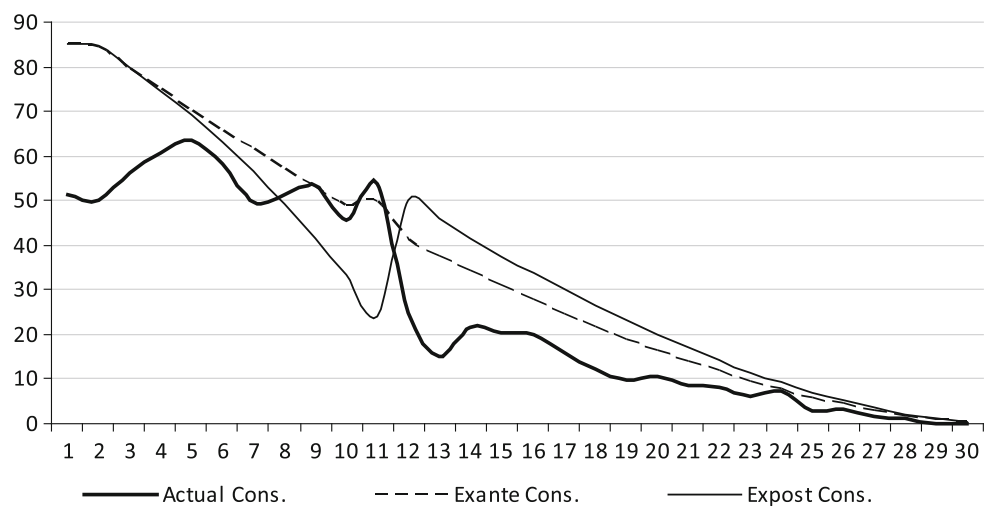

Average Consumption ( $R=10$, Neutral)

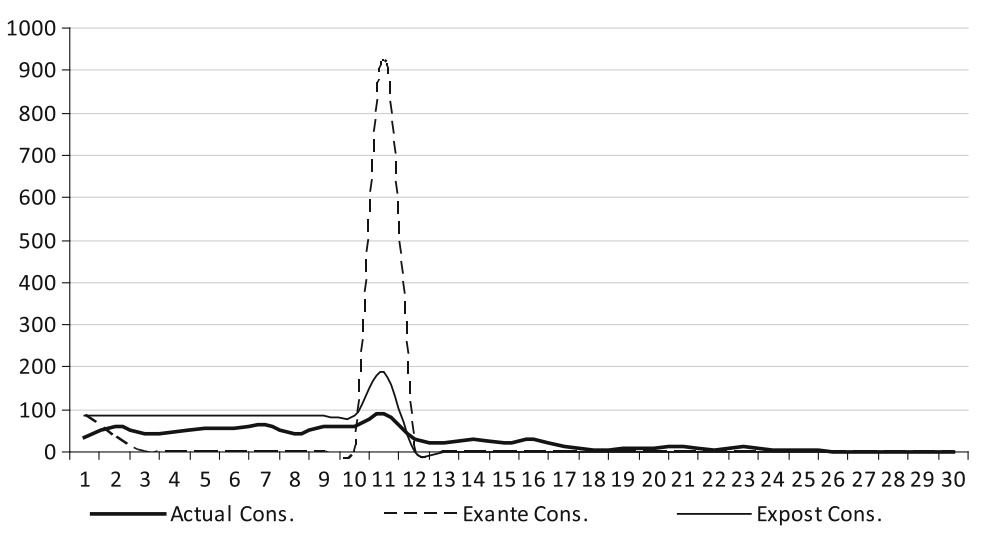

Average Consumption ( $\mathrm{R}=10$, Loving)

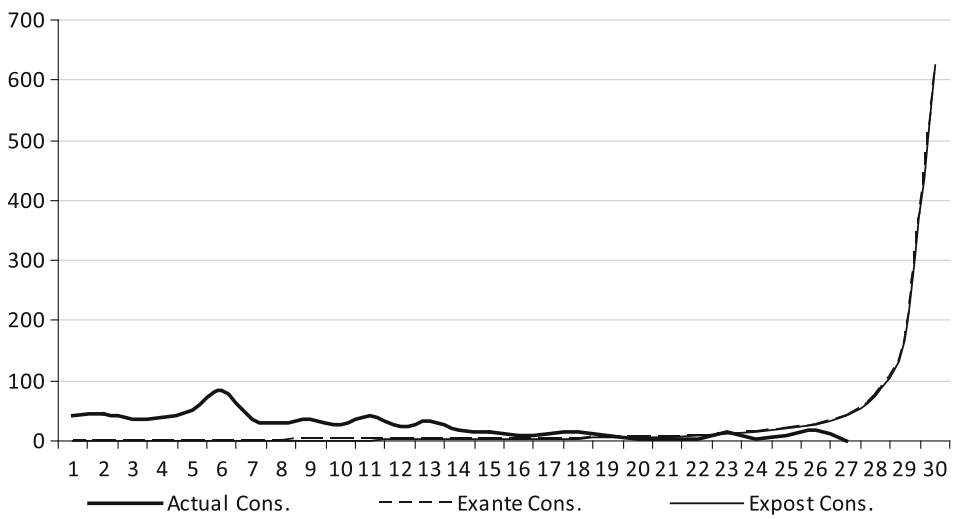

Fig. 5 Consumption in treatment LS10 (by risk aversion coefficients) 


\section{Average Cumulative Savings ( $R=10$, Averse)}

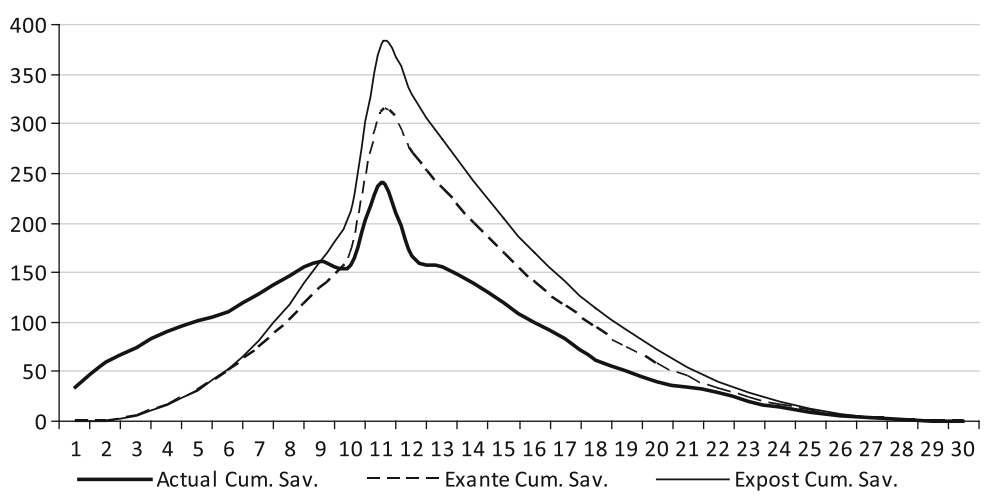

Average Cumulative Savings ( $R=10$, Neutral)

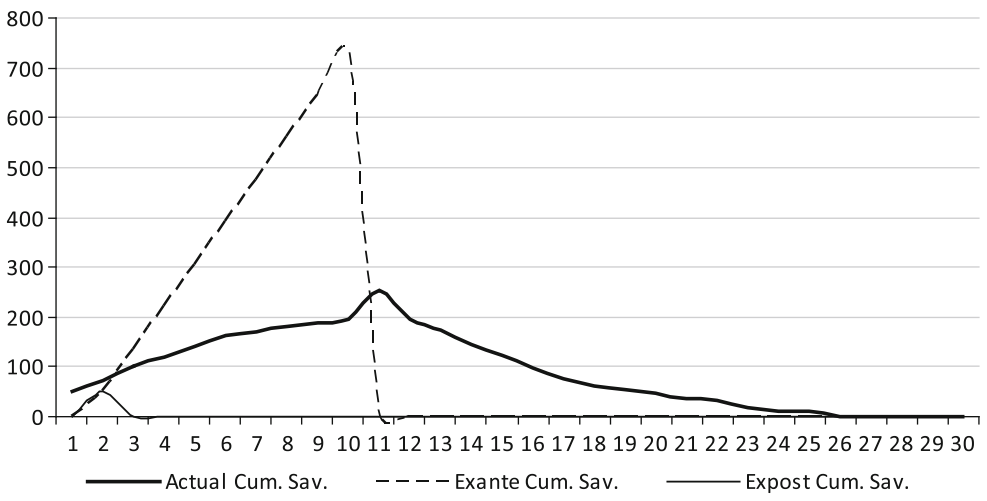

Average Cumulative Savings ( $R=10$, Loving)

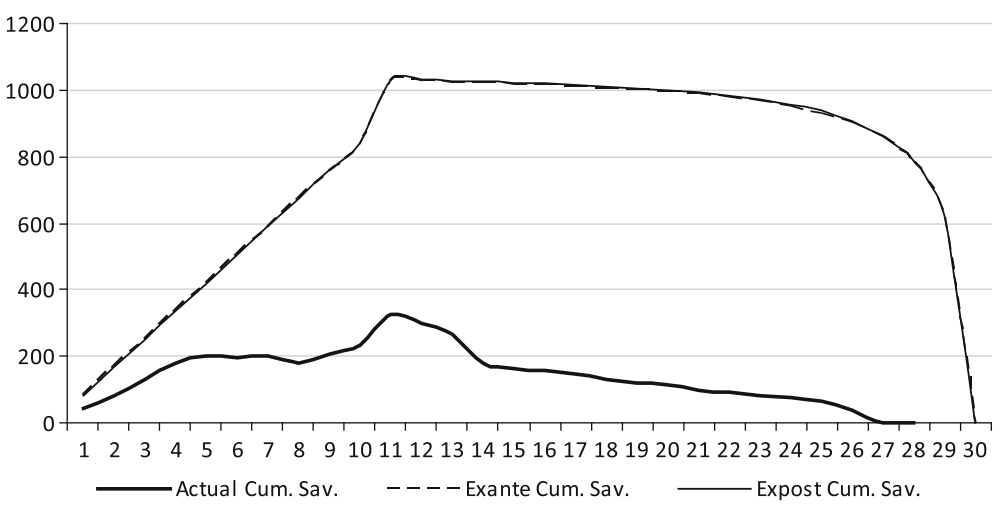

Fig. 6 Cumulative savings in treatment LS10 (by risk aversion coefficients) 
Average Consumption ( $R=15$, Averse)

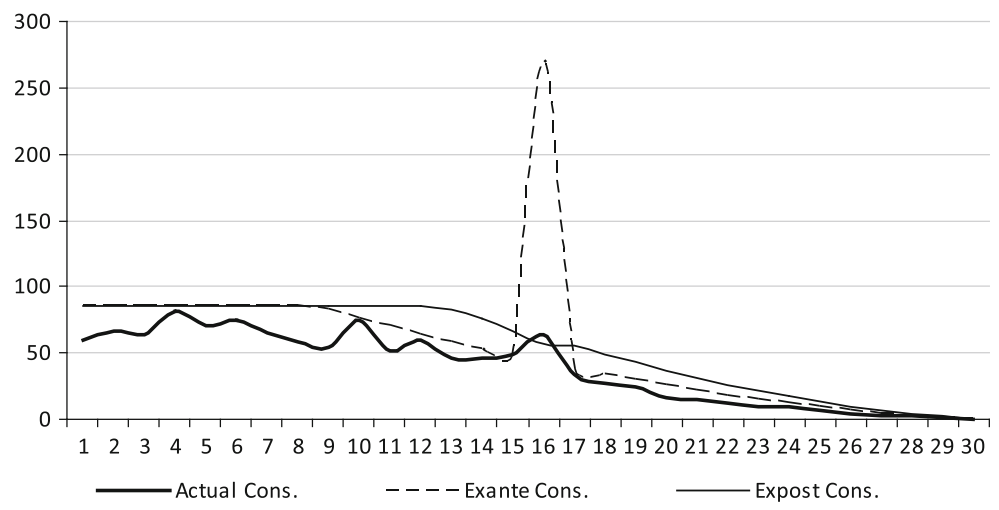

Average Consumption ( $R=15$, Neutral)

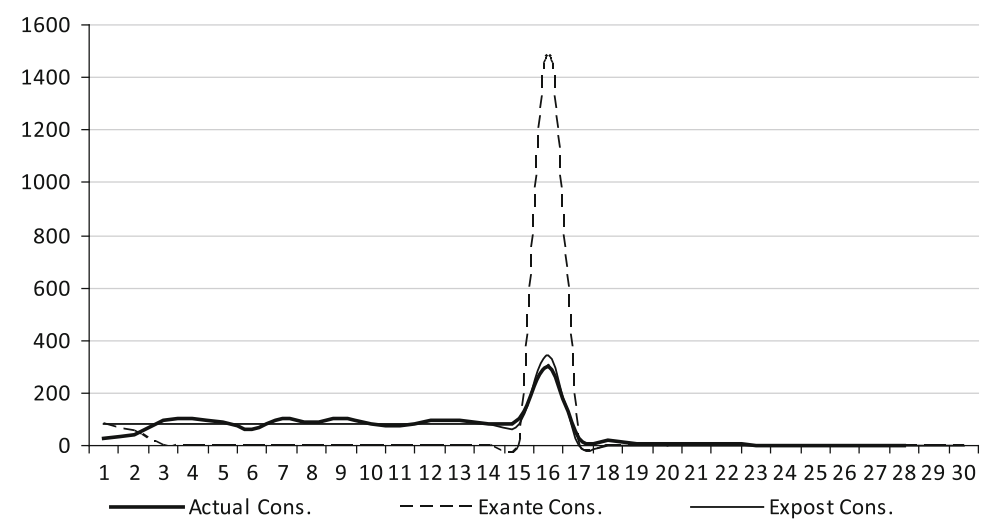

Average Consumption ( $\mathrm{R}=15$, Loving)

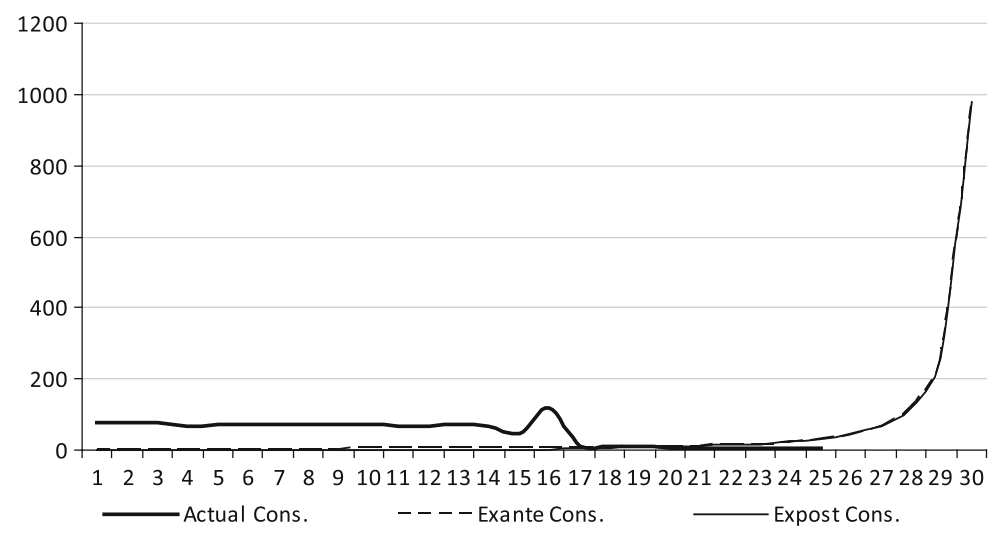

Fig. 7 Consumption in treatment LS15 (by risk aversion coefficients) 
Average Cumulative Savings ( $R=15$, Averse)

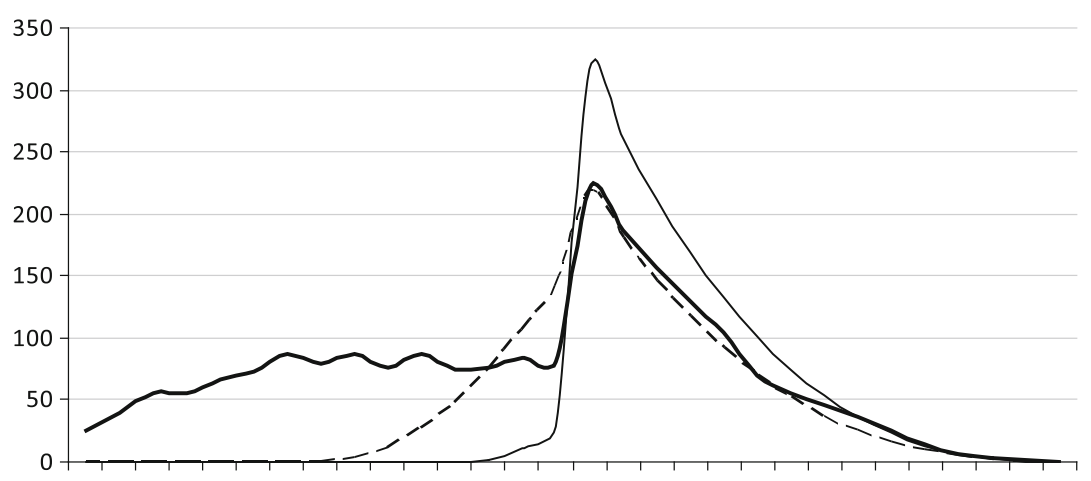

$1 \quad 2 \quad 3 \quad 4 \quad 5 \quad 6 \quad 7 \quad 8 \quad 9101112131415161718192021222324252627282930$

—-Actual Cum. Sav. - - - Exante Cum. Sav. Expost Cum. Sav.

Average Cumulative Savings ( $R=15$, Neutral)

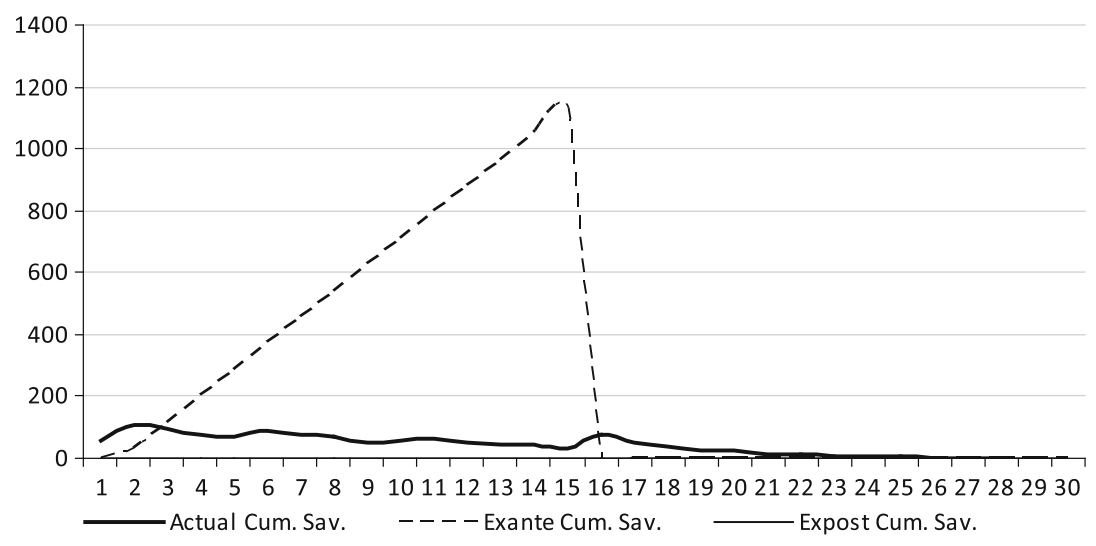

Average Cumulative Savings ( $R=15$, Loving)

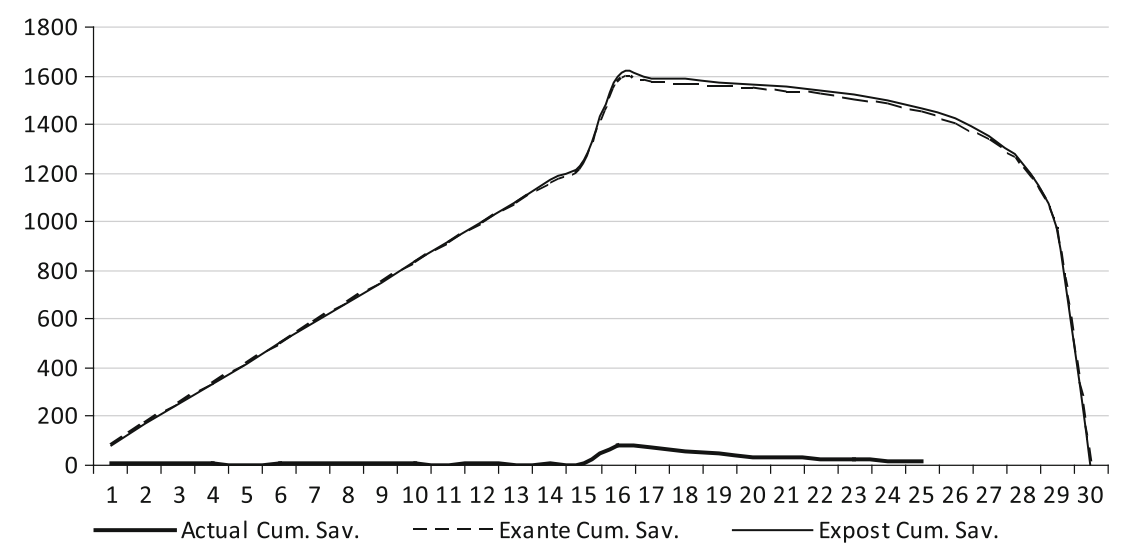

Fig. 8 Cumulative savings in treatment LS15 (by risk aversion coefficients) 


\section{References}

Agnew JR, Anderson LR, Gerlach JR, Szykman LR (2008) Who chooses annuities? An experimental investigation of the role of gender, framing, and defaults. Am Econ Rev 98:418-422

Ballinger TP, Palumbo GM, Wilcox TN (2004) Precautionary saving and social learning across generations: an experiment. Econ J 113:920-947

Blostin AP (2003) Distribution of retirement income benefits. Mon Lab Rev 126(4):3-9

Breyer F, Kifmann M (2002) Incentives to retire later: a solution to the social security crisis? J Pension Econ Financ 1:111-130

Brown A, Camerer C, Chua Z (2006) Learning and visceral temptation in dynamic savings experiments. Working Paper

Butrica B, Mermin GBT (2006) Annuitized wealth and consumption at older ages. The Center for Retirement Research WP \#2006-26

Carbone E, Hey J (2004) The effect of unemployment on consumption: an experimental analysis. Econ J R Econ Soc 114(497):660-683

Camerer C, Chua Z (2005) Experiments on intertemporal consumption with habit formation and social learning. Working Paper

Falk A, Fehr E (2003) Why labour market experiments? Labour Econ 10:399-406

Fatas E, Lacomba JA, Lagos F (2007) An experimental test on retirement decisions. Econ Inq 45(3):602-614

Fehr H, Sterkeby WI, Thorgersen O (2003) Social security reforms and early retirement. J Popul Econ 16:345-361

Fetherstonhaugh D, Lee R (1999) Framing effects and income flow preferences in decisions about social security. In: Aaron HJ (ed) Behavioral dimension of retirement economics. Brookings Institution Press, Washington, DC

Fisher J, Johnson DS, Marchand J, Smeeding TM, Torrey BB (2005) The retirement consumption conundrum: evidence from a consumption survey. The Center for Retirement Research WP \#2005-14

Gazzale R, Walker L (2009) Behavioral biases in annuity choice: an experiment. Working paper, Williams College

Hamermesh D, Menchik PL (1987) Planned and unplanned bequests. Econ Inq 25(1):55-66

Hey J, Dardadoni V (1988) Optimal consumption under uncertainty: an experimental investigation. Econ J 98(390):105-116

Holt C, Laury SK (2002) Risk aversion and incentive effects. Am Econ Rev 92(5):1644-1655

Moore JH, Muller LA (2002) An analysis of lump-sum pension distribution recipients. Mon Lab Rev 125(5):29-46

Orszag P (2001) Should a lump-sum payment replace social security's delayed retirement credit? An issue in brief. Center for Retirement Research at Boston College, no. 6

Thaler R (1992) Intertemporal choice. In: Thaler R (ed) The winner's curse: paradoxes and anomalies of economic life. Princeton University Press, Princeton, pp 50-62 